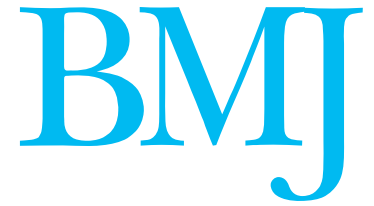

\title{
What's a good doctor, and how can you make one?
}

\author{
By marrying the applied scientist to the medical humanist
}

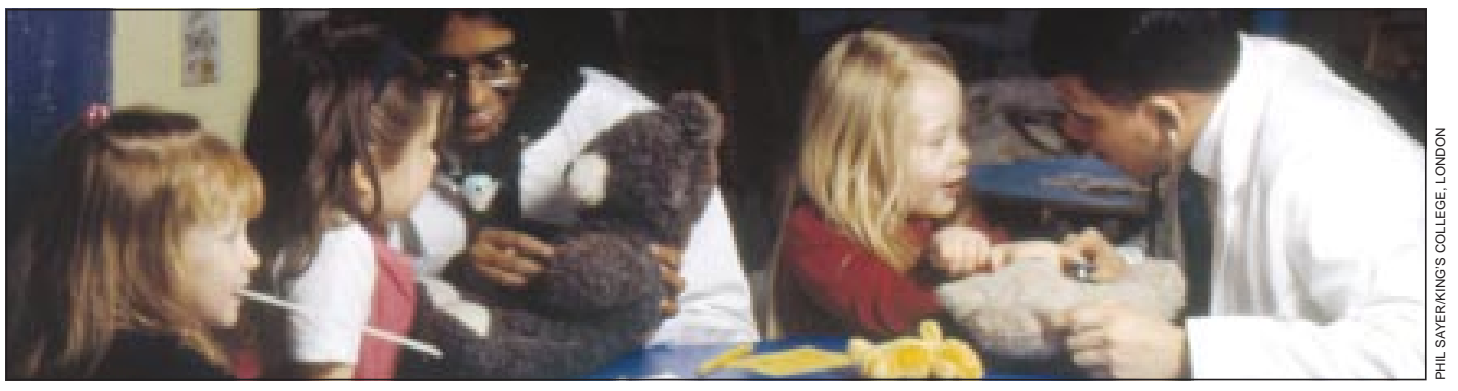

I remember the time Shipman gave to my Dad. He would come around at the drop of a hat. He was a marvellous GP apart from the fact that he killed my father. ${ }^{1}$

$\Lambda^{1}$ re you a good doctor? This question is increasingly being asked by patients, governments, third party healthcare payers, and newspaper, radio, and TV investigators. It also topped the list of suggestions for $B M J$ theme issues in a recent ballot of bmj.com users and BMA members. But why?

Claims and complaints against doctors are growing worldwide. In the United Kingdom, a series of inquiries has ushered in probably the most sustained investigation and collective appraisal of medical and healthcare institutions since the NHS began. The performance of individual clinicians, laboratory and clinical units, the frequency of medical mistakes, the unacceptability of organ retention practices, and the adequacy of death certification procedures are only a few of many medical activities now subject to intense scrutiny. ${ }^{2-8} \mathrm{~A}$ debate has thereby been prompted about the sort of doctors society wants and expects, and the need for answers is heightened by expansion in spending on medical education and health services.

One approach to defining a good doctor equates the answer with the skills of an applied scientist: good doctors combine individual clinical expertise and best available external evidence; they are thoughtful, evidence based practitioners who use "intangible personal resources" in the care of their patients. ${ }^{9}{ }^{10}$ Another approach lies buried in the Socratic dictum "Know thyself," an exhortation discernible in the importance the General Medical Council attaches to vocationalism in medicine and to the personal qualities required of its practitioners, including truthfulness and a reflective turn of mind open to audit and to learning from mistakes. Readers from 24 countries responding allude to desirable personal qualities more prominently than proficiency in knowledge and technical skills (p 715).

The psychiatrist Jeremy Holmes, writing in this issue (p 722), renders Socrates' dictum in a more modern, psychological form by acknowledging that the inner life of most doctors necessitates grappling with contradictoriness and incoherence of thoughts and feelings. If this state of affairs is the norm, reflecting on good and disapproved of aspects of the self will help doctors to become "good enough" practitioners.

But the proliferation of formal medical assessment agencies signifies that conscience and reflectivitycould they be reliably discerned-no longer offer credible guarantees of goodness in doctors. Five years ago, Richard Smith spelled out a population based rationale for setting up monitoring systems premised on the view that all doctors could potentially become problem doctors: "Think how surprised we would be by a community of 130000 (the number of doctors in Britain) where nobody committed serious crimes, went mad, misused drugs, slacked on the job, became corrupt, lost competence, or exploited their position." 11

Society and government now look towards a mix of healthcare process and outcome variables for evidence of clinical competence ( $\mathrm{p} 704$ ) and, where possible, to markers of compliance with standards, guidelines, and clinical service frameworks. Are such variables set to become surrogate measures of the goodness of practitioners?

Does the notion of goodness have anything to add to what we want from doctors once their competence and performance have been specified and verified? After all, when "good" (as an adjective) qualifies "doctor," a great deal of its meaning is determined by what is meant by "doctor." ${ }^{12}$ This, in turn, is set out in education and training curricula (p 718) and in the knowledge, competences, and values to be demon- 
strated in the process of gaining a primary medical qualification. ${ }^{13}$ When it comes to doctoring, the term "good" increasingly functions as a descriptive label that denotes having met certain tests of competency.

A poor doctor is generally credited with good intentions but inadequate knowledge or skills required for the job, and there seems little doubt that some poorly performing doctors will be picked out by performance monitoring procedures. But what about bad doctors? A bad doctor, however skilled, is one with bad intentions, undesirable values, suspectoccasionally evil-motives. Judging someone a bad doctor implies serious defects of moral agency, even though these may coexist with commendable aspects of medical practice, as the above statement from the son of one of Harold Shipman's victims makes plain. Although the death rate of Shipman's patient list turned out to be high when examined retrospectively, performance outcome measures cannot detect bad doctors in all possible circumstances.

The varieties of good, poor, and bad doctors are diverse and may sometimes coexist in the same individual. This does not make becoming a good doctor an unattainable ideal. Medical education today should be aiming to marry the skills and sensitivities of the applied scientist to the reflective capabilities of the medical humanist.
Brian Hurwitz professor of medicine and the arts

School of Humanities, King's College London, London WC2R 2LS

Alex Vass editorial registrar

BMJ

Competing interests: None declared.

1 Christopher Rudol, quoted in Barkham P. The Shipman Report. Times 2002 July 20:15

2 Report by the Comptroller and Auditor General. Handling clinical negligence claims in England. London: Stationery Office, 2001. (HC 403 Session 2000-2001 3 May 2001.)

3 Fenn P, Diacon S, Gray A, Hodges R, Rickman N. Current cost of medical negligence in NHS hospitals: analysis of claims. BMJ 2000;320:1567-71. Dyer C. GPs face escalating litigation. BMJ 1999:318:830

5 Meyers AR. "Lumping it": the hidden denominator of the medical Meyers AR. "Lumping it": the hidden denominator
malpractice crisis. Am J Public Health 1987 77:1544-8.

6 Bristol Royal Infirmary Inquiry. Learning from Bristol: the report of the pub lic inquiry into children's heart surgery at the Bristol Royal Infirmary 1984-1995. London: Stationery Office, 2001. (CM 5207.) www.bristolinquiry.org.uk/ (accessed 20 Sep 2002)

7 Department of Health. An organisation with a memory. London: Stationery Office 2000.

8 Department of Health. Building a safer NHS. London: Stationery Office 2001

9 Sackett DL, Rosenberg WMC, Muir Gray JA, Hayes RB, Richardson WS Evidence based medicine: what it is and what it isn't. BMJ 1996;312:71-2 10 Oxman AD, Chalmers I, Sackett DL. A practical guide to informed consent to treatment. BMJ 2001;323:1464-6.

11 Smith R. All doctors are problem doctors. BMJ 1997;314:841.

12 von Wright GH. The varieties of goodness. London: Routledge and Kegan Paul, 1963.

13 General Medical Council. Tomorrow's doctors. London: GMC, 2002.

\section{Patients' views of the good doctor}

\section{Doctors have to earn patients' trust}

$\mathrm{M}$ ost doctors are good doctors in the eyes of most patients. Despite the media's fixation with medical errors and damaged patients, doctors come high in the popularity stakes in almost any poll, compared with other professions or trades. ${ }^{1}$ Furthermore, familiarity tends to breed contentment, not contempt. Patients who have recent experience of medical care tend to give higher, less critical ratings than patients whose experience is less current. ${ }^{2}$ The medical profession does, however, attract criticism from patients-sometimes deservedly so.

Since the 1970s patients' groups, and women's health groups in particular, have drawn attention to the deficiencies of the traditional medical model and its tendency to demean and disempower patients. ${ }^{3}$ The reaction of the early antipaternalists was to emphasise self education and self help as a way of redressing the power imbalance between doctors and patients and avoiding dependence on orthodox medicine. It is often forgotten that most healthcare is self care, ${ }^{4}$ but too often the manner of healthcare delivery serves to increase dependency and undermine coping skills. Nevertheless, despite the feminist critique, the practitioners of orthodox medicine remain as firmly on their pedestals as ever.

What do patients want? Both interpersonal relations and technical skill are rated highly. A systematic review of the literature on patients' priorities for general practice care was conducted as part of a project by the European Task Force on Patient Evaluations of General Practice (EUROPEP). ${ }^{5}$ The most highly rated aspect of care was "humaneness." This was followed by "competence/accuracy," "patients' involvement in decisions," and "time for care." Similar themes have been identified in other studies that used different methods to derive patients' priorities. For example, patients in Scotland placed greatest importance on having a "doctor who listens and does not hurry me, ${ }^{, 6}$ and provision of information and opportunities for participation feature highly in most studies of patient satisfaction or dissatisfaction. ${ }^{7}$ Patients increasingly expect to participate in decisions about their care, but these aspirations are rarely met. $^{8}$ Failures in communication and incorrect assumptions about patients' preferences are surprisingly common. ${ }^{9}$

Doctors and patients don't always agree on priorities. A study from the Netherlands found that patients gave much higher priority to sufficient consultation time, availability of appointments at short notice, and being given detailed information about their illness, whereas doctors tended to place greater emphasis on coordination of care, home visits, and continuity. ${ }^{10}$ Perhaps this insistence by doctors on the primary importance of continuity - the central tenet of the ethos of the family doctor-is just another example of medical paternalism. The patient wants to be an informed and empowered consumer, but the doctor prefers a long term relationship with a docile patient.

Patients' ratings of doctors' interpersonal skills are strongly related to trust. Most patients want to be able to trust the health professionals they consult, but this does not mean they want to be deceived about the 